\title{
EDTA-induced platelet hypogranulation: beware of dysplasia mimic!
}

\author{
Muntadhar Al Moosawi ${ }^{1}$ (D) $\cdot$ Ayesha Vawda ${ }^{1,2} \cdot$ Audi Setiadi $^{1,3}$
}

Received: 13 January 2021 / Accepted: 15 February 2021 / Published online: 23 February 2021

(C) The Author(s), under exclusive licence to Springer-Verlag GmbH, DE part of Springer Nature 2021

\begin{abstract}
A blood sample from a 14-year-old female was submitted to our hospital hematology laboratory in a BD Vacutainer ${ }^{\circledR}$ ethylene diamine tetra-acetic acid (EDTA)anticoagulated tube $(1.8 \mathrm{mg}$ EDTA $/ \mathrm{ml})$ for complete blood count $(\mathrm{CBC})$ analysis. Apart from being treated for iron deficiency, the patient was otherwise healthy. The sample was processed within 2 hours after collection and no sample clotting was detected. The CBC showed elevated mean cell volume (MCV) of $98 \mathrm{fL}$ (age-adjusted reference range: 77-92 fL), but otherwise normal hemoglobin $(137 \mathrm{~g} / \mathrm{L})$, $\mathrm{RBC}$ count $\left(4.19 \times 10^{12} / \mathrm{L}\right)$, platelet count $\left(186 \times 10^{9} / \mathrm{L}\right)$ with normal mean platelet volume (MPV) at $11.0 \mathrm{fL}$, and white blood cell count $\left(4.8 \times 10^{9} / \mathrm{L}\right)$ with normal differential. An automatically prepared blood film by Sysmex XN9000 analyzer and stained with Wright stain was submitted for evaluation. The blood film was prepared within 2 hours of sample collection and it revealed platelets of normal size and number, but numerous hypogranular platelet forms were noted. There were no dysplastic features in the neutrophils or any degenerative changes in other cell lines (Fig. 1a; objective $\times 50$, Wright stain). The findings of macrocytosis and platelet hypogranulation raised the concern of myelodysplasia; however, the lack of cytopenia and the patient's age makes this less likely. Consideration for a congenital platelet disorder such as gray platelet syndrome was also raised, but it is usually associated with large platelet size. There is no bleeding or family history of platelet
\end{abstract}

Muntadhar Al Moosawi

m.almoosawi@alumni.ubc.ca

1 Department of Pathology and Laboratory Medicine, University of British Columbia, Vancouver, British Columbia, Canada

2 Division of Hematology, Lifelabs, Burnaby, British Columbia, Canada

3 Division of Hematopathology, British Columbia Children's Hospital, Vancouver, Canada disorders. $\mathrm{CBC}$ was then repeated 3 weeks later at another laboratory, this time in both $3.2 \%$ trisodium citrate tube and an EDTA tube $(1.8 \mathrm{mg}$ EDTA $/ \mathrm{ml})$ in parallel. The repeat EDTA sample $\mathrm{CBC}$ again showed mildly elevated MCV $(96 \mathrm{fL})$ and mild thrombocytopenia $\left(131 \times 10^{9} / \mathrm{L}\right)$ with a slightly elevated MPV (12.7 fL). Platelet count in the citrate-anticoagulated sample was $134 \times 10^{9} / \mathrm{L}$. The samples were processed within 5 hours of the collection time using the automated method by Sysmex XN-9000. They were stored in a validated temperature-controlled environment between the collection and the processing time. The blood films revealed similar hypogranular platelets in the sample collected in the EDTA tube while normal platelet morphology was observed in the citrate-anticoagulated sample (Fig. 1b; objective $\times 40$, Wright stain). Again, no dysplasia in other cell lines or degenerative changes noted. Electron microscopy was not performed.

Although EDTA-induced platelet satellitism or agglutination is commonly described, isolated artifactual platelet hypogranulation due to EDTA is a very rare phenomenon. EDTA-induced morphologic changes are also well described in the setting of excessive concentration of EDTA and excessive storage, neither of which was a factor in both our initial and repeat samples. A plasma factor is thought to be responsible for EDTA-induced platelet degranulation, possibly an immunoglobulin that is distinct from the EDTA-sensitive antibodies causing aggregation [1]. A study reported electron microscopy findings in a similar case demonstrating EDTA-induced degranulation, as well as release of CD62P by flow cytometry analysis, suggesting that EDTA-induced early platelet degranulation is the mechanism of this rare phenomenon [1]. Recognition of this artifact is crucial to avoid misdiagnosis of myelodysplasia or gray platelet syndrome. Correlation with other $\mathrm{CBC}$ indices and clinical findings can aid in identifying this artifact and repeat testing in $3.2 \%$ trisodium citrate tube is recommended to assess for normal platelet granulation. Electron microscopy can 


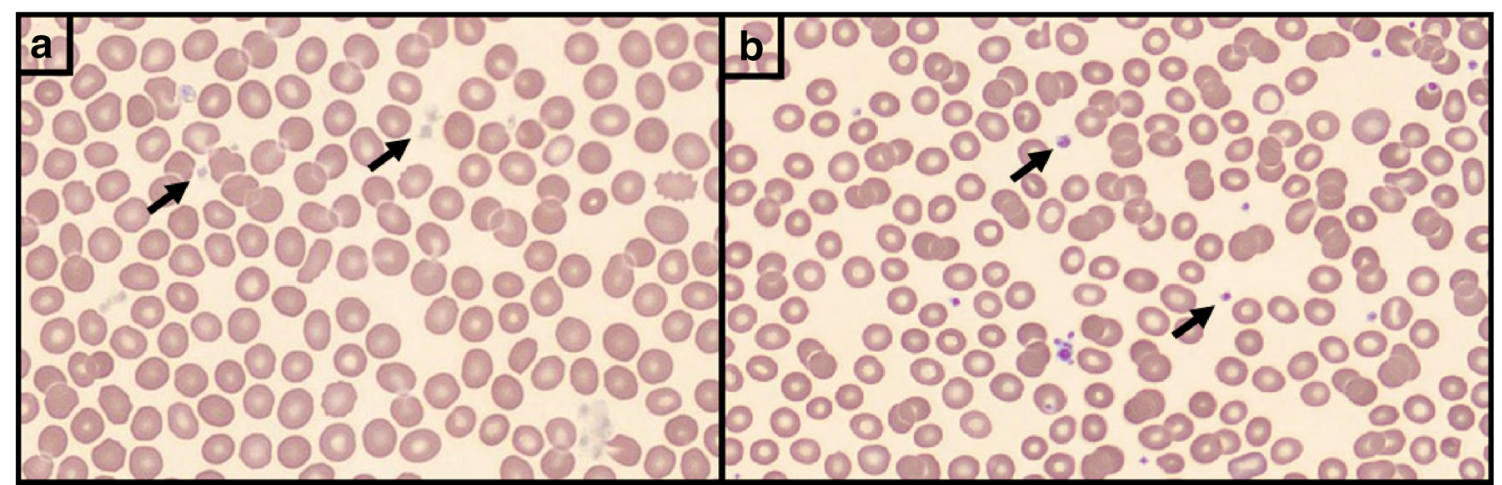

Fig. 1 Peripheral blood smear demonstrating numerous EDTA-induced hypogranular platelets (a) and normal platelet morphology in the citrateanticoagulated sample (b)

also be used to differentiate this artifact from true gray platelet syndrome caused by $N B E A L$ gene mutation.

\section{Declarations}

Conflict of interest The authors declare no competing interests.

\section{Reference}

1. Lesesve JF, Latger-Cannard V, Lecompte T (2005) Pseudo-storage pool disease due to platelet degranulation in EDTA-collected peripheral blood: a rare artifact. Clin Lab Haematol. 27(5):336-342

Publisher's note Springer Nature remains neutral with regard to jurisdictional claims in published maps and institutional affiliations. 